\title{
El Colegio de Abogados Católicos como parte del activismo de la nueva derecha católica en México
}

\author{
Tania Hernández Vicencio*
}

\section{Resumen}

\begin{abstract}
El objetivo de este artículo es hacer un primer análisis del papel que jugó el Colegio de Abogados Católicos como parte de una amplia movilización de organizaciones de la derecha católica en la Ciudad de México, con relación a temas controversiales de la agenda pública y en el proceso de cambio del significado de la laicidad del Estado mexicano. Se destaca la relevancia de los abogados como activistas de la agenda conservadora, y en particular de la derecha católica en el México de fines del siglo XX y principios del XXI, y en un contexto de disputa por establecer los criterios para la interpretación del tema de los derechos humanos y por fijar el contenido jurídico de los mismos.
\end{abstract}

Palabras clave: Colegio de Abogados Católicos, activismo conservador, derecha católica, laicidad, derechos humanos.

\section{Abstract}

The objective of this article is to make a first analysis of the role played by the Catholic Bar Association as a part of a mobilization of Catholic Right organizations in Mexico City, in relation to controversial issues of the public agenda and in the process of changing the meaning of the laicity of the Mexican State. It highlights the relevance of lawyers as activists of the conservative agenda, especially of the catholic right in Mexico at the end of the 20th century and the beginning of the 21st, and in a context of dispute to establish the criteria for the interpretation of the human rights issue and to determine the content legal nature of them.

Keywords: Catholic Bar Association, conservative activism, catholic right, laicism, human rights.

\footnotetext{
* Profesora-investigadora de la Dirección de Estudios Históricos del Instituto Nacional de Antropología e Historia.
} 


\section{Introducción}

El papel de los abogados en la conformación de la derecha mexicana es un asunto poco estudiado, ${ }^{1}$ y la relevancia de este grupo de profesionales como activistas de la nueva movilización de la derecha católica de fines del siglo XX y principios del XXI, es un tema de investigación en ciernes. Ha sido con la incorporación de la figura de los derechos humanos al debate político contemporáneo, lo que ha implicado atender la centralidad de sus dimensiones sociojurídica y sociopolítica (Estévez y Vázquez, 2017: 13) y reconocer que alrededor de esta agenda se genera un campo de disputa por establecer los criterios para su interpretación (Peláez, 2017: 56), que quedó en evidencia la relevante función que habrían de cumplir los abogados por sus conocimientos y expertise en el campo del derecho constitucional e internacional.

Una parte de este grupo de profesionales se ha convertido en activista de la causa conservadora (Vecchioli, 2009: 41). El activismo conservador consiste en complejas formas en que sectores de diversas tradiciones religiosas se politizan particularmente en defensa de un modelo de familia y sexualidad que consideran amenazado, así como en torno a todos los temas de la agenda pública con los que dicha relación mantiene vínculos estrechos y que replantean la relación entre lo religioso y lo político (Vaggione, 2012: 58). Dentro de ese marco, la nueva movilización de la derecha católica en México, como en otros países, consiste en la articulación de estrategias diferenciadas por parte de una amplia gama de actores colectivos e individuales que retoman elementos de la lucha histórica de la Iglesia católica, pero que también incorporan novedosos aspectos discursivos, programáticos y organizacionales que les permiten vincularse con una red

\footnotetext{
${ }^{1}$ Tres trabajos importantes sobre el papel de connotados abogados en la formación de proyectos sociales, políticos y educativos de la primera mitad del siglo XX mexicano, son los de Beatriz Urías Horcasitas (2016 y 2017), que aborda los casos de Rodulfo Brito Foucher y Luis Chico Goerne; y el de María Teresa Gómez Mont, sobre Manuel Gómez Morín. Los tres personajes fueron rectores de la Universidad Nacional Autónoma de México; en particular Gómez Morín tuvo una influencia fundamental en el desarrollo de la derecha política al fundar el Partido Acción Nacional.
} 
más amplia de actores internacionales con el fin de incidir en la legislación, en la elaboración de políticas públicas y en el ejercicio de gobierno (Hernández, 2019a: 22).

La nueva movilización de la derecha católica en México hace un uso estratégico del discurso sobre los derechos humanos y mantiene un trabajo más acucioso en el terreno jurídico, despliega una eficiente estrategia de cabildeo y de construcción de alianzas públicas y privadas, y se posiciona en la arena pública como un actor fundamental de la política contemporánea; sus integrantes, más que estar interesados en incidir en los programas e ideario de los partidos políticos, actúan como parte de los llamados lobbies conservadores (Pichardo y Cornejo, 2017: 1) de acción nacional e internacional. La nueva movilización de la derecha católica en México se integra por un amplio sector de la jerarquía eclesiástica y las tradicionales organizaciones de laicos, los nuevos movimientos eclesiales, organizaciones nacionales e internacionales Pro Vida, agrupaciones civiles de ideología conservadora, líderes de partidos políticos, un sector de los legisladores federales y locales, y de funcionarios y gobernantes de todos los niveles, así como de un sector de jueces y funcionarios de los aparatos de impartición de justicia (Hernández, 2019a: 22).

El objetivo de este artículo es hacer una primera caracterización y un análisis preliminar del papel que jugó el Colegio de Abogados Católicos en la articulación de varias acciones de la nueva derecha católica, particularmente en la capital del país, con relación a temas controversiales de la agenda pública y en importantes procesos de cambio constitucional. La idea es que en el periodo 2005-2013, es decir, entre el año de la fundación del CAC y la introducción del principio de libertad religiosa en la Constitución Federal, esta organización fue un elemento importante no sólo para la expresión pública de los reclamos de una amplia red de actores, sino también porque por su actuación hizo patente de forma pública que la disputa jurídica es ya un elemento central del activismo conservador en México. 


\section{El nacimiento del Colegio de Abogados Católicos}

En las últimas décadas del siglo XX, en México, como en otros países de América Latina, observamos la articulación de un nuevo "activismo religioso conservador" (Vaggione, 2005) -que involucra a varios credos, pero el católico es su principal protagonista- que ha mostrado que la participación de las organizaciones de laicos y de grupos diversos de la sociedad civil de ideología conservadora debe ser considerada parte del activismo político contemporáneo, que actúa en pro de sus legítimas demandas y que, en ese sentido, el desarrollo público de sus actividades tiene el objetivo de influir en los debates, las políticas y las legislaciones nacionales (Vaggione, 2010: 14). De acuerdo con Blancarte, en un contexto de importantes cambios sobre el tema de la laicidad, por la que ésta ha dejado de concebirse como la tajante separación de las esferas política y religiosa, el fenómeno religioso en muchos países ya es concebido como parte de los procesos sociales y culturales, por lo que también se acepta con mayor naturalidad que los dirigentes eclesiales, de las organizaciones de laicos y grupos afines a las iglesias, tienen derecho a expresarse y a tratar de influir de forma legítima en las políticas públicas, incluso como parte del proceso democrático (Blancarte, 2008: 14). La condición indispensable para que así sea, es que los dirigentes políticos, los representantes populares y los funcionarios de gobierno tomen decisiones basadas en la premisa de que su autoridad deriva del mandato popular y que los representantes religiosos no terminen por imponer sus criterios en el contenido de las políticas públicas (Blancarte, 2008: 14) que involucran a personas de distintos credos o no creyentes.

En México, la posibilidad de que las redes de la derecha católica se expresaran de forma pública con mayor naturalidad en la disputa de temas específicos se dio por lo menos por tres razones. La primera razón fue que las reformas constitucionales de 1992 incorporaron una idea de laicidad positiva, ${ }^{2}$ dejando atrás el concepto de laicidad

\footnotetext{
${ }^{2}$ Los artículos reformados fueron: el 3 (sobre la educación), 50 (sobre las órdenes monásticas), 24 (sobre la libertad de culto), la fracción II del 27 (sobre la posesión de bienes por parte de las iglesias) y el 130 (sobre la personalidad jurídica de las iglesias).
} 
excluyente que históricamente había prevalecido, gracias a la cual se reconoció la personalidad jurídica de las iglesias, que había sido negada en el Artículo 130 de la Constitución de $1917,{ }^{3}$ y con lo que las instituciones eclesiásticas adquirieron derechos y obligaciones frente a terceros y podían obrar legalmente. En México, las medidas impuestas en la Constitución del 17 pretendían desaparecer el poder religioso en la esfera pública y en la construcción de la sociedad que se intentaba forjar en el siglo XX (Blancarte, 2008: 33). El no reconocimiento jurídico de las iglesias, la prohibición para que poseyeran bienes, las limitaciones al culto externo fuera de los templos, la imposibilidad de constituir partidos políticos con referencias religiosas y las prohibiciones para que los ministros de culto participaran en actividades políticas, fueron medidas con las que se intentó disminuir la fuerza de las iglesias, pero especialmente de la Iglesia católica, y contribuir a la construcción del Estado laico, es decir a un sistema político que prescindió en buena medida durante el siglo XX de formas de legitimación provenientes de las instituciones religiosas. Después de un acuerdo implícito de tolerancia denominado modus vivendi, en México prevaleció un Estado que formal y discursivamente trató de preservar para sí el espacio público, sobre todo en el terreno de la organización social y política, pero permitió mayor libertad de la iglesia en el ámbito educativo, bajo formas diversas de tolerancia y disimulo (Blancarte, 2008: 33-34).

Cuando los gobiernos fueron perdiendo legitimidad, tuvieron que acudir a alianzas con otras fuentes de legitimidad, como la religiosa, para mantener el poder

\footnotetext{
${ }^{3}$ Con estas reformas se avanzó en materia de Derecho Eclesiástico del Estado y por lo tanto en la relación que éste tiene con las distintas confesiones religiosas y con el principio de la libertad religiosa en sus distintas dimensiones. Anteriormente, la legislación no contemplaba en el ordenamiento legal la existencia jurídica de las iglesias, situación que la Iglesia católica, sus grupos de laicos y organizaciones afines consideraban atentatorio de la libertad religiosa. A partir de ese momento, la fuentes formales del Derecho Eclesiástico en México fueron las reformas constitucionales, la Ley Reglamentaria llamada Ley de Asociaciones Religiosas y Culto Público y su reglamento; también son parte de las bases jurídicas los instrumentos internacionales que el Estado mexicano signó en materia de derechos humanos, así como varias resoluciones dictadas por la Secretaría de Gobernación a través de la Subsecretaría de Asuntos Jurídicos y Religiosos, además de las sentencias dictadas por los distintos tribunales del Poder Judicial de la Federación (Rodríguez, 2009: 2).
} 
político. Esta situación favoreció a una creciente presencia pública de la jerarquía católica y a una mayor presión sobre el sistema político. De ahí que las reformas constitucionales de 1992 abrieran la posibilidad para el retorno de las iglesias al espacio público, ya no sólo de la católica, pues para este momento México ya experimentaba un incipiente proceso de crecimiento de otros credos. Y aunque se reiteró el principio histórico de separación entre el Estado y las Iglesias y se mantuvo el espíritu original liberal de la Carta Magna, las instituciones eclesiásticas, pero sobre todo la católica, consideraron que era el momento de ejercer presión y comenzar a influir en la definición de las leyes y políticas públicas de la Nación (Blancarte, 2008: 34-35). Es decir, en México se avanzó desde el punto de vista histórico, político, cultural y jurídico en destrabar lo que Taylor ha considerado como un asunto central de las democracias modernas, que es concebir a la religión como un problema traicionando incluso valores democráticos esenciales como el reconocimiento de la pluralidad y la tolerancia. En opinión de este autor, la idea de fetichizar los acuerdos históricos en las sociedades contemporáneas ha evitado ver al régimen secular en una perspectiva más fructífera por la que se acepte el lugar importante que ocupan las creencias o filosofías de vida en la identidad de los ciudadanos (Taylor, 2014: 70). Según Taylor, la posibilidad de adoptar un modelo de laicidad abierta, más empática con el asunto de los derechos humanos, que no atente contra la identidad moral de la persona y que visibilice las creencias, favorece la integración cívica. La solución, dice Taylor, no es despojar a las sociedades de sus señas de identidad religiosa, sino asumir que hay distintas formas de concebir la laicidad lo que implica permitir el reacomodo de los grupos sociales dentro de un marco negociado, dentro de los límites del derecho, y de ahí la necesidad de aceptar que la convivencia social pasa por la construcción de un consenso constante que implica intentar arreglos institucionales que promuevan, ante todo, la libertad de creencias (Taylor, 2014: 77).

La segunda razón por la que en décadas recientes ha sido posible una nueva movilización de la derecha católica en México tiene que ver con el impulso que ésta ha recibido de una amplia estructura internacional (Lemaitre, 2013: 9), proceso que empata 
con la centralidad que han cobrado temas controversiales de la agenda nacional que deben traducirse en política pública, por ejemplo, la despenalización del aborto, los matrimonios entre personas del mismo sexo, la eutanasia, los vientres subrogrados, la investigación con células madre o la adopción por parte de matrimonios de personas del mismo sexo. La nueva movilización de la derecha católica debe observarse como un rasgo novedoso de la reacción frente al orden secular que caracterizó a las sociedades contemporáneas, pues además de replantear la discusión sobre la laicidad, entra al debate de temas concretos que muestran una nueva politización de lo religioso focalizada en la relación sexualidad y política (Vaggione, 2005).

La articulación de una amplia red de actores conservadores puede comprenderse a la luz de las Ilamadas coaliciones de abogacía (Sabatier, 1988, Sabatier y Jenkins, 1993 y 1999) o también llamadas coaliciones de causa o coaliciones promotoras (Gómez Lee, 2012: 11), que aluden a alianzas entre personas y grupos sociales actuando en distintas posiciones de la toma de decisiones, las cuales comparten un particular sistema de creencias y percepción de un problema, y muestran un grado de actividad coordinada a lo largo del tiempo para alcanzar objetivos concretos (Sabatier, 1993: 25), como puede ser la lucha por la continuidad o por el cambio de una política pública. Aunque la categoría coaliciones de causa ha sido usada especialmente para el análisis de comportamientos de actores antisistema (Hatcher, 2008: 176), lo que me interesa retomar aquí es el énfasis que se pone en la idea de que detrás de las acciones y estrategias de los actores existe una ideología, una cosmovisión, que se traduce en la defensa de una causa. En este tipo de alianzas estratégicas el papel de los abogados o abogados de causa será fundamental por su rol proactivo en el campo jurídico y por su compromiso con ideas y valores de una agenda específica (Sarat y Scheingold, 1998: 7).

La tercera razón tiene que ver con el ascenso al gobierno federal del derechista Partido Acción Nacional en el año 2000, en contraste con el ejercicio de gobierno de un partido de izquierda, el Partido de la Revolución Democrática, en la capital del país, a cuyo 
amparo se impulsaron varias iniciativas de ley con relación a temas de la agenda de los derechos sexuales y reproductivos. En agosto de 2000, apenas cuatro meses antes de que iniciara el primer gobierno federal panista, encabezado por Vicente Fox (2000-2006), la Jefa del Gobierno del Distrito Federal, Rosario Robles, promovió ante la Asamblea Legislativa del entonces $\mathrm{DF}^{4}$ una ley para despenalizar el aborto por cuestiones eugenésicas y si el embarazo hubiese sido producto de la inseminación artificial no consentida. Como una primera reacción y asumiendo la defensa de los derechos humanos, uno de los primeros logros de los legisladores y asesores jurídicos conservadores fue que en 2001 se adicionó un tercer párrafo al Artículo 10 de la Constitución Federal con el que se asentó que quedaba prohibida la discriminación por motivos religiosos. Un año después, en 2002, la Diputada independiente de la II Legislatura de la Asamblea del Distrito Federal y entonces presidenta de la Comisión de Derechos Humanos, Enoé Uranga, ${ }^{5}$ presentó la iniciativa original sobre la Ley de Sociedades de Convivencia en el Distrito Federal, a la que los miembros de la fracción parlamentaria del PAN en la ALDF y algunos miembros del Partido Revolucionario Institucional se opusieron tajantemente (Hernández, 2011: 368). En ese ambiente de tensión, el impulso de iniciativas de ley de corte progresista en el entonces Distrito Federal generó un efecto demostración y una alerta en los grupos conservadores sobre la posibilidad de que las iniciativas impulsadas en la capital pudiesen extenderse a otras entidades del país, de ahí la necesidad de organizar un grupo de abogados que dieran la pelea en el terreno legal.

\footnotetext{
${ }^{4}$ En este trabajo se usa la denominación Distrito Federal y Ciudad de México indistintamente, ya que el 5 de febrero de 2016, por Acuerdo General del Pleno del Consejo de la Judicatura Federal, se estableció el cambio de denominación de la capital del país, pasando de Distrito Federal a Ciudad de México. Diario Oficial de la Federación.

Disponible en http://www.dof.gob.mx/nota_detalle.php?codigo $=5424565 \&$ fecha $=05 / 02 / 2016$ [última consulta: 1 de agosto de 2018].

${ }^{5}$ Después de años de confrontaciones entre promotores y opositores, la ley entraría en vigor hasta 2006.
} 
Si bien la Iglesia católica mexicana y en especial la Arquidiócesis de México históricamente han tenido un staff de asesores legales para atender sus litigios, el Colegio de Abogados Católicos, creado en 2005 en la Ciudad de México, empezó a constituir un puente a través del cual era posible una vinculación más amplia y fluida por parte de las estructuras de la Iglesia con sus grupos de laicos y con una diversidad de organizaciones de la sociedad civil. EI CAC también es expresión de lo que se ha llamado la "revolución de los derechos" (Epp, 1998), es decir, del proceso por el cual la movilización social con relación a distintas causas usa los saberes de los profesionales de la abogacía que participan en distintas instancias para judicializar causas colectivas en defensa de sus principios y valores morales. EI CAC, de alguna forma ha pretendido emular las estrategias de organizaciones similares de Italia, Francia, Argentina y España. Su actual dirigente es el abogado Armando Martínez Gómez, quien es licenciado en Derecho por la Universidad Anáhuac México Sur, una universidad del sistema educativo de Los Legionarios de Cristo (1941), maestro en Acción Política y Participación Ciudadana en el Estado de Derecho por el Centro Universitario Francisco de Victoria, Universidad Rey Juan Carlos, Universidad Miguel Hernández y el Ilustre Colegio de Abogados de Madrid, y doctor en Gestión Estratégica y Políticas del Desarrollo. Actualmente, es profesor de la Universidad Anáhuac, la Universidad Pontificia de México y la Universidad del Pedregal. ${ }^{6}$

Desde su fundación, el CAC planteó la necesidad de actuar en un nuevo contexto de apertura en pro de la libertad religiosa. Este objetivo cobró mayor fuerza cuando, en 2006, el también panista Felipe Calderón ganó la elección presidencial, y, como su antecesor, creó fuertes expectativas a las iglesias para realizar una nueva reforma del Artículo 24 e incluir el principio de libertad religiosa. En ese contexto, el CAC se propuso realizar un trabajo en dos etapas: la primera, consistía en establecer un plan de orientación y cambio de cultura de la sociedad mexicana con relación al tema de la

\footnotetext{
${ }^{6}$ Información tomada de su blog Martínez Gómez, Armando (n/d). Armando Martínez Gómez. Datos personales [en línea]. Disponible en armandomartinezgomezblogspot.mx [última consulta: 4 de julio de 2017].
} 
libertad religiosa, y la segunda fase avanzaría en la creación de un modelo jurídico para establecer los mecanismos idóneos de consulta y para el ejercicio de acciones legales preventivas antes de tomar decisiones jurídicas sobre dicho tema. ${ }^{7}$ El CAC también anunció que su intención era convertirse, con el aval del Arzobispado Primado de México, entonces encabezado por el Cardenal Norberto Rivera Carrea, en una Asociación Pública de Fieles Laicos que contribuyera a la recuperación y al mantenimiento de los principios cristianos en la filosofía y la ciencia del derecho, en la actividad legislativa, judicial y administrativa, en la enseñanza y en la investigación, así como en la vida pública y profesional. ${ }^{8}$ Los objetivos concretos del CAC se plantearon en los siguientes términos:

a) “Proveer el Bien Común mediante la Asunción de los valores morales contenidos en la Doctrina y el Magisterio de la Iglesia Católica, intentando que estos regulen las acciones de los individuos de la sociedad."

b) "Defender y difundir privada y públicamente los principios de dicha doctrina y de dicho magisterio."

c) "Contribuir al mejoramiento del orden jurídico positivo sobre la base de los principios del Derecho Natural."

d) "Defender al clero en el ejercicio de sus actividades profesionales y representarlos ante el estado y sus demás sociedades intermedias y particulares".

e) "Difundir la doctrina y la enseñanza social de la Iglesia, principalmente en el terreno jurídico, e indagar sobre los medios que aseguren su aplicación." 9

El activismo del CAC, y de una amplia red de organizaciones de la derecha católica de alcance nacional, se agudizó cuando el 16 de noviembre de 2006 finalmente fue publicada en la Gaceta Oficial del Distrito Federal la Ley de Sociedad de Convivencia promovida años atrás y a partir de ese momento se abrió un nuevo debate en torno al aborto. En la ALDF fueron presentadas tres iniciativas que abonaban a su despenalización

\footnotetext{
${ }^{7}$ Catholic.net. (2017) "Colegio de Abogados Católicos de México" en Catholic.net [en línea]. Disponible en es.catholic.net/op/artículos/13596/cat/215/colegio-de-bogados-catolicos-de-mexico-html [última consulta: 3 de julio de 2017].

${ }^{8}$ Ibidem.

${ }^{9}$ Ibidem.
} 
hasta la décimo segunda semana de gestación y que motivaron las reacciones inmediatas de los sectores conservadores. El 23 de noviembre de 2006, en sesión ordinaria del Pleno de la ALDF, el diputado Armando Tonatiuh González Case, del Partido Revolucionario Institucional, presentó una iniciativa que implicaba cambios en varios artículos del Código Penal y de la Ley de Salud del Distrito Federal. ${ }^{10}$ El 6 de marzo de 2007, en sesión de la Comisión de Gobierno de la ALDF, los diputados Jorge Carlos Díaz Cuervo y Enrique Pérez Correa, del Partido Social Demócrata y Campesino, presentaron una iniciativa de decreto por la cual se derogaban diversas disposiciones del Código Penal y el Código Civil del Distrito Federal. ${ }^{11}$ Posteriormente, el 30 de marzo de 2007, el presidente de la Comisión de Administración y Procuración de Justicia de la ALDF, el diputado perredista Daniel Ordóñez, presentó un proyecto de dictamen de reformas al Código Penal y a la Ley de Salud. ${ }^{12}$

Y es que como afirma Vaggione (2013: 5), lejos de replegarse frente a los debates legales, el activismo religioso conservador ha reforzado su presencia en la arena pública y ha desplegado nuevas estrategias para recuperar el control sobre la legalidad y la

${ }^{10}$ La iniciativa consistía en la reforma de los artículos 145, 146, y la derogación del 147 y 148 del capítulo V del Código Penal del Distrito Federal; así como la reforma del artículo 14, fracción II, y el anexo de la fracción $X$ del Artículo 2 y los artículos 14 bis 1,14 bis 2, 14 bis 3, 14 bis 4,14 bis 5, 14 bis 6 y se derogan los artículos 16 bis 6 y 16 bis 7 de la Ley de Salud del Distrito Federal. Los detalles en Asamblea Legislativa del Distrito Federal (2006) Diario de los Debates [en línea]. Disponible en: http://www.aldf.gob.mx/archivo9887913d9dc2e666377cb0924917cd81.pdf

${ }^{11}$ Se proponía la iniciativa de reforma de los artículos 145 y 147 del Código Penal para el Distrito Federal. Los detalles en Asamblea Legislativa del Distrito Federal (2007) Iniciativa de Reforma a los artículos 145 y 147 del Código Penal para el Distrito Federal [en línea]. Disponible en: http://docplayer.es/15594774-Ivlegislatura-w-e-mexico-gob-mx-wb2-emex-emex_gaceta_oficial_del_gobierno_del_df.html [última consulta: 3 julio de 2014].

${ }^{12}$ La iniciativa, según Ordoñez, reunía elementos de las presentadas por los otros diputados, y básicamente se avanzaba en el compromiso del gobierno para difundir políticas sociales y educativas tendientes a la promoción de la salud reproductiva y de sus derechos sexuales, así como en el derecho de la mujer para alegar ante el médico circunstancias derivadas de dificultades económicas o problemas familiares que le impidieran seguir con el embarazo, y el mandato de que las instituciones públicas de salud del Gobierno del DF, gratuitamente y en condiciones de calidad, deberían proceder a la interrupción del embarazo. Romero, Gabriela (2007) "Presentan formalmente a comisiones el proyecto de despenalización del aborto" en La Jornada [en línea]. Disponible _http://www.jornada.unam.mx/2007/03/31/index.php?section=capital\&article=033n1cap [última consulta: 13 de julio de 2014]. 
legitimidad de la sexualidad (Vaggione, 2013: 23). La politización reactiva de lo religioso describe a una serie de desplazamientos en la articulación entre religión y política, que en la práctica ha implicado evitar cambios en las leyes para vaciar de legitimidad las reformas realizadas o, por el contrario, abonar a la judicialización de distintas políticas públicas para interrumpir su impacto (Vaggione, 2013: 25).

El 11 de marzo de 2007 el CAC anunció, desde la Catedral Metropolitana, sede de la Arquidiócesis Primada de México, que llevaría a cabo una movilización contra las acciones de los asambleístas para despenalizar el aborto, ${ }^{13}$ y que mantendría encuentros con las distintas fracciones legislativas de la ALDF para exigir que los diputados se comprometieran con la defensa de la cultura de la vida y no de la muerte. Su dirigente afirmó también que, en caso de que se aprobara la iniciativa en materia de aborto, el CAC recurriría al recurso de la controversia constitucional ante la Suprema Corte de Justicia de la Nación. ${ }^{14}$ Días más tarde, la Arquidiócesis Primada de México, la Unión Nacional de Padres de Familia (1917) y la organización Somos Vida llevaron a cabo la primera peregrinación a la Basílica de Guadalupe, en el marco del III Congreso Internacional Provida, ${ }^{15}$ movilización a la que se sumaron algunos grupos protestantes e incluso miembros del ejército mexicano. Como parte de la coordinación de la marcha, el dirigente del CAC, Armando Martínez, se expresó en los siguientes términos: "Vamos a movilizar a los católicos y a todas las religiones y saldremos a la calle a defender la vida [...] no a favor

\footnotetext{
${ }^{13}$ León, Gabriel (2007) "Anuncia la Iglesia movilizaciones en favor de la vida" en La Jornada [en línea]. Disponible en: http://www.jornada.unam.mx/2007/03/12/index.php?section=capital\&article=044n2cap [última consulta: 12 de marzo de 2007].

${ }^{14}$ La Redacción (2007) "Se apoyará a la iglesia católica contra la despenalización del aborto: PAN-DF" en Proceso [en línea]. Disponible en: http://www.proceso.com.mx/206213/se-apoyara-a-la-iglesia-catolicacontra-la-despenalizacion-del-aborto-pan-df [última consulta: 15 de septiembre de 2017].

${ }^{15}$ La manifestación se desarrolló en el marco del III Congreso Internacional Provida celebrado en la Ciudad de México del 23 al 25 de marzo de 2007.
} 
de la cultura de la muerte que se quiere hacer ahora [...] si no lo han entendido con la negociación política, esperemos hacerlos entender en la calle."16

El CAC también demandó la realización de referéndums en los que la ciudadanía expresara su opinión con relación al tema del aborto, por lo que, en abril de 2007, el CAC difundió en su sitio web el formato para recoger firmas y solicitar la realización de una consulta popular en la que la población de la capital del país decidiera si estaba a favor o en contra de la despenalización del aborto. El objetivo era recolectar el $0.5 \%$ de firmas de personas empadronadas para solicitar a la ALDF la realización del referéndum, tal como establecía la Ley de Participación Ciudadana del entonces DF; la solicitud fue considerada improcedente por el Instituto Electoral del Distrito Federal que encontró varias irregularidades en la recolección de las firmas. ${ }^{17} \mathrm{~A}$ pesar de esto, el dirigente del CAC siguió organizando protestas públicas y estuvo presente en debates con legisladores y académicos argumentando en contra de la reforma.

Cuando el 24 de abril de 2007, en el Distrito Federal se aprobaron las reformas a la Ley de Salud y al Código Penal, con el fin de despenalizar el aborto durante las primeras doce semanas de embarazo, ${ }^{18}$ el presidente del CAC solicitó formalmente a la Procuraduría General de la República que promoviera ante la Suprema Corte de Justicia de la Nación un recurso de inconstitucionalidad respecto al decreto que despenalizaba el

\footnotetext{
${ }^{16}$ Flores, G., (2007) "Colegio de abogados católicos anuncia movilizaciones para impedir que legisladores de la Asamblea del DF legalicen el aborto" en Noticieros Televisa [en línea]. Disponible en: http://www.esmas.com/noticierostelevisa/mexicano/610659.html [última consulta: 10 septiembre de 2017].

${ }^{17}$ Alcaraz, Yetlaneci y González, María de la Luz (2007) "Improcedente referéndum sobre el aborto: IEDF" en El Universal [en línea]. Disponible en: http://archivo.eluniversal.com.mx/ciudad/84137.html [última consulta: 13 de junio de 2007].

${ }^{18}$ Se considera que en la capital del país el aborto representa la tercera causa de muerte materna, mientras que a nivel nacional es la quinta causa de muerte de las mujeres en edad reproductiva. De acuerdo con datos publicados por Guttmacher Institute, El Colegio de México y Population Council, en 2006 la Ciudad de México reportó una tasa de aborto de 34 por cada 1000 mujeres en edad reproductiva, es decir, un porcentaje ligeramente más alto que el de la república mexicana que es de 33 por cada 1000.
} 
aborto en el DF. ${ }^{19}$ En el mes de mayo, y con el argumento de que la norma no podía permitir la privación de la vida del producto, ni discriminar su protección por la temporalidad de su gestación, la PGR, encabezada por Eduardo Medina Mora, promovió una acción de inconstitucionalidad respecto a la reforma en materia de aborto aprobada en la ALDF. Incluso la Comisión Nacional de Derechos Humanos, cuyo titular era el jurista José Luis Soberanes Fernández, abogado cercano al Opus Dei, interpuso un recurso de inconstitucionalidad para impugnar las reformas en materia penal y de salud por considerar que las modificaciones rebasaban el ámbito local y con el argumento de que el artículo 73, Fracción XVI de la Constitución, plantea que la legislación en materia de salud corresponde al Congreso de la Unión. ${ }^{20}$ Un año después, aun cuando la SCJN declaró improcedentes las demandas de inconstitucionalidad presentadas, el representante del CAC persistió en su activismo. Durante las audiencias públicas abiertas por la SCJN para escuchar voces a favor y en contra, Martínez Gómez fue el principal ponente para argumentar a favor de la inconstitucionalidad de las reformas.

De manera paralela, los grupos opositores a la despenalización del aborto hasta la décimo segunda semana de gestación desplegaron una estrategia de contención en los congresos locales, tratando de que el ejemplo del DF no se generalizara a lo largo del país. A partir de 2008 y hasta 2016 habrían de tejerse las alianzas necesarias para garantizar el derecho a la vida desde la concepción en las constituciones de 19 entidades (Hernández, 2019b). Además, impulsaron con mayor fuerza la idea de que era fundamental armonizar las leyes nacionales con los tratados internacionales en materia de derechos humanos,

${ }^{19}$ Castillo, Gustavo (2007) “Solicitan abogados católicos a la PGR promueva recurso de inconstitucionalidad”,
en $\quad$ La Jornada http://www.jornada.unam.mx/2007/05/04/index.php?section=capital\&article=042n2cap [última consulta: 10 de mayo de 2007].

${ }^{20}$ Castillo, Gustavo (2007) “Promueven PGR y CNDH ante la Corte acciones contra el aborto”, en La Jornada [en línea]. Disponible en: http://www.jornada.unam.mx/2007/05/26/index.php?section=capital\&article=028n1cap [última consulta: 10 de mayo de 2007]. 
por lo que éstos debían quedar consignados en la Constitución Federal; se trataba de un paso necesario para avanzar posteriormente hacia la modificación del Artículo 24, a fin de que fuese incluida la libertad religiosa como parte de aquéllos. En esa amplia estrategia que implicaba acciones en distintos niveles y espacios, el CAC sería un actor importante y realizaría varias actividades en coordinación con una amplia red de organizaciones de la sociedad civil, como por ejemplo Red Familia, que había sido creada en 1999 con el fin de vincular a grupos dedicados a la defensa de la familia tradicional, el derecho de los padres a decidir sobre la educación de los hijos conforme a sus principios y valores, y el principio de la vida humana desde la concepción y hasta la muerte natural. Red Familia es parte del movimiento internacional denominado Red Mundial de las Familias y de la Alianza Latinoamericana para la Familia, y en el plano nacional mantiene relación estrecha con la histórica Unión Nacional de Padres de Familia, pieza importante de la derecha social mexicana. ${ }^{21}$ Otras organizaciones que comenzaron a participar activamente en esta red fueron Unión de Voluntades México (2006), movimiento social católico a favor de la familia tradicional y la vida, integrado por los principales grupos de laicos católicos como la Unión Femenina Católica Mexicana, Adoración Nocturna, Caballeros de Colón y otras agrupaciones afines como la UNPF y la Unión Nacional Sinarquista. ${ }^{22}$ Incluyendo México (2007), cuyo objetivo es influir en la elaboración de políticas públicas en materia de educación y salud reproductiva y sexual de los jóvenes. ${ }^{23} \mathrm{Y}$ el Consejo Nacional de Laicos (2008) dedicado a coordinar la acción laical de las distintas diócesis del país; ${ }^{24}$ su objetivo

\footnotetext{
${ }^{21}$ Ver su página oficial, disponible en Red Familia (n/d) ¿Quiénes somos? [en línea]. Disponible en http://www.redfamilia.org/nosotros/quienes-somos [última consulta: 8 de marzo de 2018].

${ }^{22}$ Ver su sitio oficial, disponible en Unión de Voluntades (n/d). Unión de Voluntades [en línea]. Disponible en http://www.uniondevoluntades.org.mx/ [última consulta: 3 de octubre de 2016].

${ }^{23}$ Ver su página oficial, disponible en Incluyendo México (n/d). Fundación Incluyendo México [en línea]. Disponible en http://www.incluyendomexico.org.mx/index1.html [última consulta: 13 de junio de 2016].

24 Ver su página oficial, disponible en http://www.juntospormexico.mx/prensa/itemlist/user/800consejonacionaldelaicos, consultado el 13 de junio de 2016.
} 
es la defensa de los derechos humanos, la libertad religiosa y los valores de la familia tradicional. ${ }^{25}$

\section{El Colegio de Abogados Católicos, parte del activismo por la libertad religiosa}

Aunque en México la introducción de la figura de los derechos humanos en la Constitución Federal se dio hasta el segundo decenio del presente siglo, el uso estratégico de la práctica del derecho, como herramienta para la transformación social y política, posicionaron a los abogados como elementos clave de la política mexicana, actuando dentro del conjunto de las estructuras del Estado (Manzo, 2016: 177) y como parte de la sociedad civil. Lo que se observa actualmente en México es la conjunción de esfuerzos desde distintos ámbitos para apuntalar un activismo jurídico conservador que tiene como una estrategia central la adaptación del discurso liberal y secular para argumentar a favor de sus causas. La intervención de estos profesionales está incidiendo en la manera en que se interpretan y procesan los conflictos políticos, y su acción militante termina por influir incluso el propio universo del derecho (Vecchioli, 2009: 44). La incorporación con rango constitucional del derecho internacional de los derechos humanos, la existencia de asociaciones civiles específicamente abocadas al tratamiento judicial de causas relacionadas con aquéllos, la relevancia que han tomado las gestiones ante tribunales

\footnotetext{
${ }^{25}$ En México, otro espacio de este tipo de activismo ha sido la Comisión Mexicana de Derechos Humanos (1988), organismo de la sociedad civil, que se dice ajena a partidos políticos y a toda organización religiosa, pero cuyo objetivo es aportar una "visión del humanismo trascendente" a la lucha por la vigencia de los derechos humanos de modo que ésta incluya la defensa de la libertad religiosa, la eliminación de toda forma de discriminación, el derecho a la libertad de expresión y pensamiento, y trata de incidir en la legislación y políticas públicas para garantizar "la dignidad de la persona humana". La CMDH tiene vínculos con redes sociales en otros países, con lo que contribuye a la formación de activistas defensores de una agenda conservadora. http://www.comexdh.org.mx/conocenos/mision, consultado el 20 de abril de 2018. Como ejemplo reciente de estas actividades, la CMDH y la Barra Nacional de Abogados Cristianos, llevaron a cabo en mayo de 2018 el Programa Nacional de Libertad Religiosa, con el fin de "...atacar la incapacidad del gobierno federal y de autoridades locales de erradicar los casos de intolerancia religiosa que se registran en el país. http://www.abogadoscristianos.org/principal/index.html, consultada el 9 de junio de 2018.
} 
nacionales e internacionales en esa materia, la participación en misiones internacionales y la multiplicación de agencias estatales dedicadas a delinear políticas sobre el tema, reflejan las modificaciones ocurridas en el espacio de la militancia de estos profesionales y las transformaciones ocurridas dentro del campo del derecho (Vecchioli, 2009 :44). Así, es posible observar cómo los abogados realizan tareas como consultores, asesores, conferencistas, investigadores, académicos, litigantes o directivos de Organizaciones No Gubernamentales (Vecchioli, 2009: 50), desde donde apuntalan la agenda conservadora.

Ahora bien, en octubre de 2007, el CAC entregó al Senado de la República una propuesta de reforma de tres de los cinco artículos históricamente en disputa entre la Iglesia católica y el Estado mexicano, con el fin de avanzar hacia lo que era su concepción sobre la libertad religiosa. La propuesta tenía la siguiente redacción.

Artículo 30: "Garantizada la libertad de religión por el artículo 24, dicha educación será aconfesional; sin embargo, en la educación básica que imparta el Estado se podrá, a petición de los padres o tutores, impartir educación religiosa en las escuelas públicas, de acuerdo a la solicitud de estos mismos y respetando la no imposición de la misma".

Artículo 130: "Los ministros podrán asociarse con fines políticos. Asimismo, en reunión pública, actos de culto o de propaganda religiosa, o en publicaciones de carácter religioso, podrán oponerse a las leyes del país o a sus instituciones. No podrán agraviar, de cualquier forma, los símbolos patrios".

Artículo 24: "Toda persona tiene derecho a la libertad de pensamiento, de conciencia y de religión; este derecho incluye la libertad de cambiar de religión o de creencia, así como la libertad de manifestar su religión o creencias, individual y colectivamente, tanto en público como en privado, por la enseñanza, la práctica, el culto y la observancia." 26

\footnotetext{
${ }^{26}$ Velasco, Elizabeth (2007) "Presionan católicos para que por ley los curas puedan asociarse con fines políticos" en La Jornada [en línea]. Disponible en http://www.jornada.com.mx/2007/10/05/index.php?section=politica\&article=020n1pol, [última consulta: 5 de julio de 2017]
} 
El mismo día que fue entregada la propuesta, el Cardenal Norberto Rivera Carrera apoyó la iniciativa y afirmó que la misión de la Iglesia católica no podía supeditarse al interior de los templos y a la práctica del culto, pues tenía la obligación de orientar a sus fieles en todo lo que afectara sus vidas, incluida la política, por lo que manifestó su total apoyo a la propuesta en el sentido de que los sacerdotes pudiesen asociarse con fines políticos e incluso aspirar a cargos públicos. ${ }^{27}$

En noviembre de 2008 el dirigente del CAC fue nombrado Rector de la Universidad del Pedregal, vinculada a los Colegios La Salle de Seglares, la cual empezó a extender su presencia a otros estados del país como Aguascalientes, Baja California, Baja California Sur, Campeche, Chiapas, Chihuahua, Colima, Durango, Estado de México, Guanajuato, Guerrero, Hidalgo, Jalisco y Michoacán. Además, ya que para este momento era claro que en México la abogacía dedicada a la defensa de los derechos humanos se había convertido en una veta importante para el ejercicio de la profesión, ese mismo año se creó la Barra Nacional de Abogados Cristianos, organización que apoya a una diversidad de iglesias cristianas y evangélicas. La BNAC da asesorías a ministros de culto, pastores, líderes y laicos que consideran que sus derechos humanos han sido violentados y los apoya en el proceso legal, realiza registros de asociaciones religiosas, ingresa al país a pastores extranjeros, además de brindar representación legal a las iglesias. Entre sus objetivos están velar por la libertad de creencias, el culto religioso, la familia tradicional, y procurar el cuidado de los niños "desde que son engendrados hasta su plena formación física, moral, intelectual, espiritual y cultural". Actualmente la BNAC cuenta con delegaciones en Chiapas, Veracruz, Morelos, Tlaxcala y el Distrito Federal. ${ }^{28}$

\footnotetext{
${ }^{27}$ Notimex (2007) "Apoya Rivera Carrera que sacerdotes puedan aspirar a cargos públicos" en La Jornada [en línea]. Disponible en www.jornada.unam.mx/2007/10/05/index.php?section=politica\&article=021n1pol [última consulta: 4 de julio de 2017].

${ }^{28}$ Véase su página oficial en Barra Nacional de Abogados Cristianos (n/d). Visión y Misión [en línea]. Disponible en https://abogadoscristianos.wordpress.com/vision-y-mision/ [última consulta: 18 de septiembre de 2017].
} 
Cuando en 2011 fue reformado el Artículo 1ํㅡ, del Título I de la Constitución y fue conferido rango constitucional a los derechos humanos, se transitó de la procuración de las garantías individuales, a custodiar los Derechos Humanos y sus Garantías. En ese proceso el CAC también se involucró activamente, pues el cambio a dicho artículo abriría la puerta a la posterior argumentación a favor de la reforma del Artículo 24, para incluir la libertad religiosa como parte de los derechos humanos. La reforma por la que se incluyó la figura de los derechos humanos en la Constitución Federal definitivamente transformó la manera como se entiende el constitucionalismo en México; debido a la actual esencia principialista de la misma, se ha visto fortalecido el papel que juegan los abogados versados en la materia y el de aquellos ubicados en los órganos jurisdiccionales encargados de promoverlos, protegerlos y garantizarlos.

Bajo el constitucionalismo garantista en el que se incorporan principios como la igualdad, la dignidad de las personas y los derechos fundamentales, la moral pasa a ser parte del punto de vista jurídico o interno al derecho (Ferrajoli, 2011: 21-22), y los abogados y los jueces pasan a ser, en la práctica, parte de la "creación del derecho". La esencia principialista abre la posibilidad de una amplitud interpretativa y argumentativa que demanda de los abogados especialistas en el tema de los derechos humanos y de los juzgadores un papel más activo que el que tradicionalmente tenían (Neria, 2015: 107108). Como en otros países de América Latina, en México los tribunales han empezado a situarse en el centro del escenario político y los jueces están redefiniendo políticas públicas decididas por autoridades representativas, mientras que los ciudadanos y las organizaciones sociales están usando a la ley para posicionar demandas colectivas (Smulovitz, 2008: 287). Si bien en otros países del continente Americano el papel protagónico que los jueces están asumiendo en los procesos judiciales se ha venido estudiando de forma más sistemática a partir de lo que se denomina "activismo judicial" (Maraniello, 2012: 46), en México esta dimensión del activismo social es parte de una incipiente reflexión. En este sentido, ha destacado sobre todo el papel que han tenido los 
magistrados de la Suprema Corte de Justicia de la Nación al tener que resolver varias controversias constitucionales y acciones de inconstitucionalidad interpuestas por distintos actores políticos a raíz del proceso de despenalización del aborto en la capital del país que -como he mencionado- entre 2008 y 2016 detonó cambios constitucionales en los congresos locales, por lo que el sistema federal mexicano experimentó fuertes tensiones (Hernández, 2019b).

Es muy importante señalar que, a lo largo de este proceso de articulación de una nueva derecha católica, de la que es parte el CAC, los sectores liberales del Congreso de la Unión que consideraban que el principio de laicidad del Estado mexicano, tal como había sido concebido en la Constitución de 1917, se encontraba amenazado, retomaron viejos esfuerzos por incluir a la laicidad como principio de la República Mexicana y en 2012 lograron concretar su objetivo al modificar el contenido del Artículo 40, que actualmente establece que: "Es voluntad del pueblo mexicano constituirse en una República democrática, representativa, laica y federal compuesta por Estados libres y soberanos en todo lo concerniente a su régimen interior, y por la Ciudad de México, unidos en una federación establecida según los principios de esta ley fundamental." 29

En ese contexto el activismo conservador cobró nuevo impulso, por lo que ese mismo año nació la Unión Nacional de Movimientos Católicos que desde entonces realiza anualmente el evento "Juntos por México", en el que se coordinan acciones para trabajar en pro de la "edificación del Reino de Dios en el mundo". La iniciativa para formar la UNMC había surgido cuatro años antes, dentro del Encuentro de Presidentes y Asistentes Nacionales de Movimientos y Asociaciones Laicales, convocado por la Dimensión Laicos de la Conferencia del Episcopado Mexicano. La idea era crear una gran agrupación que articulara a las organizaciones laicales católicas en México en defensa de la libertad

\footnotetext{
${ }^{29}$ El texto vigente puede verse en Instituo de Investigaciones Jurídicas (2017) Constitución Política de los Estados Unidos Mexicanos - Ordenamiento - Legislación. [en línea]. Disponible en https://www.juridicas.unam.mx/legislacion/ordenamiento/constitucion-politica-de-los-estados-unidosmexicanos [última consulta: 18 de septiembre de 2017].
} 
religiosa y de los valores de la familia tradicional, y que contribuyera a la transformación de las estructuras sociales en coordinación con instituciones afines. ${ }^{30}$

Tras articular a una amplia red de actores en pro de la reforma al Artículo 24, en el mes de junio de 2013 finalmente éste fue modificado por lo que su contenido quedó como sigue:

Toda persona tiene derecho a la libertad de convicciones éticas, de conciencia y de religión, y a tener o adoptar, en su caso, la de su agrado. Esta libertad incluye el derecho a participar, individual o colectivamente, tanto en público como en privado, en las ceremonias, devociones, o actos del culto respectivo, siempre que no constituyan un delito o falta penados por la ley. Nadie podrá utilizar los actos públicos de expresión de esta libertad con fines políticos, de proselitismo o de propaganda política. El Congreso no puede dictar leyes que establezcan o prohíban religión alguna. ${ }^{31}$

Los cambios constitucionales de 2013 contribuyeron a una visión distinta sobre la laicidad en México. Si con las modificaciones de la década de los noventa se había pasado de una laicidad excluyente a una laicidad abierto o positiva (Poulat, 2012: 24), con los cambios constitucionales recientes y en un contexto en el que los gobiernos, e incluso algunos candidatos a cargos de elección popular, tienden a buscar alianzas con actores que les proporcionan nuevas fuentes de legitimación, incluidas las religiosas, se abre la posibilidad de que en los hechos se construya un tipo de "laicidad de colaboración" por la que el Estado defiende su autonomía frente a las iglesias, pero acepta e incluso procura su colaboración en terrenos específicos (Bauberot y Milot, 2011: 352). Ya que el rasgo

\footnotetext{
${ }^{30}$ Ver su página oficial, disponible en Juntos por México (n/d). ¿Quiénes somos? [en línea]. Disponible en http://www.juntospormexico.mx/quienes-somos [última consulta: 5 de mayo de 2018].

${ }^{31}$ El texto vigente puede verse en Instituto de Investigaciones Jurídicas (2017) Constitución Política de los Estados Unidos Mexicanos - Ordenamiento - Legislación. [en línea]. Disponible en https://www.juridicas.unam.mx/legislacion/ordenamiento/constitucion-politica-de-los-estados-unidosmexicanos [última consulta: 18 de septiembre de 2017].
} 
principal de este tipo de laicidad es la promoción de la libertad religiosa de los grupos y su expresión en la esfera pública, en la práctica podrían ver afectados los principios de equidad, neutralidad del Estado y hasta el de libertad de conciencia, toda vez que las autoridades religiosas, a través de distintos medios, querrán incidir en la política pública (Blancarte, 2013: 12), y los sectores conservadores dentro de las instituciones del Estado podrían evadir el cumplimiento de determinadas obligaciones, contraviniendo la igualdad jurídica entre los ciudadanos so pretexto de acatar convicciones personales (Castro, 2015: 47).

El nuevo ambiente de mayor apertura contribuyó a la creación de nuevas organizaciones conservadoras. En 2015 nació Conciencia Nacional por la Libertad Religiosa, A.C., cuyo objetivo es actuar en la promoción y defensa de los derechos humanos relacionados con la familia, la libertad religiosa y la objeción de conciencia, de pensamiento, de expresión y de asociación, mediante la difusión, asesoría, capacitación e investigación en la materia para lo cual se fortalecen lazos en distintos órdenes y niveles de gobierno, asociaciones y sociedad civil. Esta organización trabaja de manera conjunta con otros grupos de la sociedad civil en el diseño de políticas y propuestas legislativas tendientes a garantizar la libertad religiosa y la objeción de conciencia. ${ }^{32}$ Ese año también se creó la Fundación Aguirre, Azuela, Chávez, Jauregui Pro Derechos Humanos, integrada por dos ex ministros de la Suprema Corte de Justicia de la Nación, Sergio Aguirre Anguiano y Mariano Azuela Güitrón, ambos de perfil conservador. El primero, ex regidor en el Cabildo de Guadalajara, Jalisco y ex candidato a Diputado Federal por el PAN y cercano al Opus Dei; el segundo un activista pro vida, que asistió a la Decimocuarta Jornada de Debate por la Legalización del Aborto en Argentina y participó activamente en el 14o Plenario de Comisiones del Congreso de la Nación, manifestando su posición en contra de

\footnotetext{
32 Véase su página oficial en Conciencia Nacional por la Libertad Religiosa (2016) Nosotros [en línea]. Disponible en http://www.conciencianacional.org/nosotros.php [última consulta: 5 de mayo de 2018].
} 
la despenalización del aborto. ${ }^{33}$ La Fundación oferta la experiencia y capacidad de sus integrantes en "emisión de opiniones y litigio estratégico"; los ex magistrados se presentan como "personas comprometidas con la transformación de un México incluyente, con valores sólidos y preocupados por el tema de los derechos humanos, con base en su correcta interpretación y aplicando el principio Pro Persona". ${ }^{34}$

El CAC, por su parte, en el extremo del pragmatismo de su dirigente, en 2015 intentó obtener una candidatura ciudadana para contender por la Diputación Federal por el Distrito XXIII de la Ciudad de México. Según Armando Martínez, fue la corriente Vanguardia Progresista ${ }^{35}$ del partido de izquierda PRD la que lo invitó a participar en la contienda interna, en reconocimiento de su compromiso con la participación ciudadana y por tener experiencia en la instrumentación de formas ciudadanas de participación política como el referéndum y el plebiscito. Ante la oposición que encontró en el PRD al buscar una candidatura ciudadana, en 2016 Martínez Gómez logró un espacio en la Asamblea Legislativa de la Ciudad de México como Diputado Constituyente Suplente del Diputado Luis Alejandro Bustos Olivares, del Partido Verde Ecologista de México, quien es especialista en temas constitucionales, de derechos humanos y de libertad de expresión. Además, el CAC comenzó a explorar la posibilidad de vincularse con organizaciones internacionales para obtener capacitación. En 2016, el CAC y la Asociación de Abogados Católicos de Italia firmaron un convenio para impulsar programas de investigación y

\footnotetext{
${ }^{33}$ Véase Boletín Año XVIII, № 1108 (29 de mayo de 2018). Aborto: 14ㅇ Plenario de Comisiones, consultado el 23 de agosto de 2018.

${ }^{34}$ Véase su página oficial en Fundación Aguirre, Azuela, Chávez, Jáuregui, Pro Derechos Humanos, A.C. (2016). Fundación [en línea]. Disponible en https://www.aayasoc.mx/fundacion.html [última consulta: 5 de mayo de 2018].

${ }^{35}$ A esta corriente pertenecen los perredistas Eduardo Venadero Medinilla, Héctor Serrano y Roberto López, entre otros, que actualmente impulsan la candidatura de Miguel Ángel Mancera como posible candidato del denominado Frente Amplio Democrático para la presidencia de la república en 2018.
} 
formación de académicos. ${ }^{36}$ También se ha acercado a la Unión Internacional de Juristas Católicos, ${ }^{37}$ la cual actualmente reúne a las asociaciones de Argentina, Australia, Brasil, Canadá, Chile, España, Francis, Italia, Luxemburgo, Malasia, Filipinas, Polonia, Portugal y Suiza.

En junio de 2016, se abriría una carpeta de investigación sobre la actuación del Cardenal Norberto Rivera Carrera quien fue investigado por "conspiración para la pederastia". En ese litigio el representante legal de la Arquidiócesis y presidente del CAC, Armando Martínez, también se vio involucrado al ser denunciado de defender a varios clérigos acusados del delito de pederastia en varios estados donde también fungía como apoderado legal, como en el caso de la Arquidiócesis de San Luis Potosí. ${ }^{38}$ Envuelto en el escándalo y desde que en diciembre de 2017 el Cardenal Rivera dejó la Arquidiócesis Primada de México, el dirigente del CAC si bien disminuyó su activismo, no desapareció de la escena pública y se abocó a participar en la movilización de la derecha católica a propósito del proceso electoral de julio de 2018.

\section{Comentarios finales}

A lo largo de este trabajo insistí en el papel relevante que en México, como en otros países Latinoamericanos, ha cobrado el desempeño de los abogados en el activismo

\footnotetext{
36 Gaudium Press América Latina (2016) “Abogados católicos de México e Italia firman convenio" en Gaudium Press [en línea]. Disponible en es.gaudiumpress.org/content/83472-Abogados-catolicos-deMexico-e-Italia-firman-convenio [última consulta: 3 de julio de 2017].

37 Véase Unión Internacional de Juristas Católicos (n/d) “Unión Internacional de Juristas Católicos. Presentación, principios fundamentales composición, responsabilidades y actividades públicas" en Catholic.net [en línea]. Disponible en http://es.catholic.net/op/articulos/591/cat/215/union-internacionalde-juristas-catolicos.html [última consulta: 18 de septiembre de 2017].

${ }^{38}$ Rivera, Astrid (2017) “Investigan al cardenal Norberto Rivera por presunto encubrimiento de pederastas" en El Universal [en línea]. Disponible en http://www.eluniversal.com.mx/articulo/nacion/seguridad/2017/07/6/indaga-pgr-cardenal-por-caso-de pederastas [última consulta: 5 de julio de 2017].

Barranco, Bernardo (2015) “El extraño abogado del cardenal Rivera” en La Jornada [en línea]. Disponible en www.jornada.unam.mx/2015/01/28/politica/019a2pol [última consulta: 4 de julio de 2017].
} 
de una amplia red de actores conservadores. La incorporación de la agenda sobre los derechos humanos, y en especial sobre los derechos sexuales y reproductivos, reactivó a las tradicionales organizaciones de la Iglesia católica a movilizarse en pro de su agenda conservadora, pero también incentivó el nacimiento de una diversidad de actores colectivos e individuales que tratan, por distintos medios, de influir en la elaboración de las políticas públicas, de las leyes y en el ejercicio de gobierno. En tanto que parte fundamental del debate y la disputa por el contenido de la agenda sobre los derechos humanos tiene que ver con su dimensión jurídica, el ejercicio de la abogacía con relación a ese tema se torna más relevante. Los argumentos jurídicos manejados por los abogados que participan en la nueva movilización de la derecha católica retoman elementos de las viejas disputas de la Iglesia, pero también del debate secular, para argumentar jurídicamente en favor de sus causas. En el caso de México, los cambios recientes a la Constitución en materia de derechos humanos y de libertad religiosa ya han comenzado a mostrar la relevancia que tendrá este grupo de profesionales en el ejercicio de su profesión y al actuar como juzgadores, pues sus acciones están teniendo impactos concretos en la interpretación y aplicación de las leyes.

En esta perspectiva, es posible decir que la pertinencia de observar el desempeño del CAC radica por lo menos en tres aspectos. Primero, porque en la historia de la derecha mexicana es un ejemplo claro del activismo jurídico conservador que nace justo en el contexto de la consolidación de la agenda sobre los derechos humanos y con una clara y pública intención de defender la agenda conservadora. Segundo, porque el CAC es una muestra de la ruta de la judicialización de las demandas que caracteriza al activismo de la nueva derecha católica mexicana. Tercero, porque si bien el activismo del CAC ha disminuido considerablemente, a lo largo de diez años su dirigente fue capaz de desplegar diversas estrategias de acción y coordinar en la Ciudad de México varias movilizaciones e iniciativas de la derecha católica, además de promover acercamientos con funcionarios y legisladores, movilizarse en las calles y mantenerse activo en los medios de comunicación. 
Cuarto, porque a su desempeño debió haber contribuido el vínculo estrecho que su dirigente mantenía con el entonces titular de la Arquidiócesis Primada de México, situación que pudo posibilitar el acercamiento con políticos y funcionarios de distintos partidos.

Será importante indagar sobre el desarrollo futuro de esta organización y, a partir de su experiencia, seguir la pista de otras organizaciones de abogados que han surgido en otras entidades del país y que actualmente se mantienen activas en la disputa por la agenda pública. Además de los casos de la Barra Nacional de Abogados Cristianos y de la Fundación Aguirre, Azuela, Chávez, Jáuregui Pro Derechos Humanos, será menester observar a grupos como la Asociación de Abogados Católicos de Mérida, Yucatán, Abogados Católicos de Jalisco, la Barra de Abogados Católicos de Guanajuato o la Asociación de Abogados Católicos de Querétaro, todas éstas creadas al inicio del presente siglo.

\section{Bibliografía}

BAUBEROT, J. ; MILOT, M . 2011. Laïcités sans frontières. Paris, Seuil.

BLANCARTE, R. 2008. "El porqué de un Estado laico" en Roberto Blancarte (coord.), Los retos de la laicidad y la secularización en el mundo contemporáneo. México, El Colegio de México, pp. 29-46.

BLANCARTE, R. 2013. Laicidad en México. Colección de Cuadernos Jorge Carpizo. Para entender y pensar la laicidad, Núm. 31, México, UNAM/ Instituto de Investigaciones Jurídicas/ Cátedra Extraordinaria Benito Juárez/Instituto Iberoamericano de Derechos Constitucional.

CASTRO PÉREZA, R. 2015. El reconocimiento constitucional del derecho humano de objeción de conciencia. Mexicali, Baja California, Universidad Autónoma de Baja California.

EPP, C. R. 1998. The Rigths Revolution. Lawyers, Activists, and Supreme Courts in Comparative Perspective. Ltd. London, University of Chicago Press.

ESTÉVEZ, A.; VÁZQUEZ, D. (Coords). 2017. Razones para (des)confiar de las luchas por los derechos humanos. México, FLACSO/UNAM. 
FERRAJOLI, L. 2011. "Constitucionalismo principialista y constitucionalismo garantista" en DOXA, Cuadernos de Filosofía del Derecho. No. 32, pp. 15-53.

GÓMEZ LEE, M. I. 2012. "El marco de las coaliciones de causa-Advocay Coalition Framework" en Revista Opera. No.12, pp.11-30.

GóMEZ MONT, M. T. 1996. Manuel Gómez Morín: la lucha por la libertad de cátedra. México, Fondo de Cultura Económica.

HATCHER, L. J. 2008. “Abogacía legal ¿Por la derecha? Conservadores, ideología y activismo social” en Pensamiento Jurídico [en línea], No. 22. Disponible en http://www.revistas.unal.edu.co/index.php/peju/article/view/38174 [última consulta: 3 de marzo de 2018].

HERNÁNDEZ VICENCIO, T. 2011. "El Partido Acción Nacional en la lucha por la no despenalización del aborto en el Distrito Federal" en Andamios. Vol. 8, No.15, pp. 367-369.

2019a. "La movilización de la derecha católica mexicana entre el final del siglo XX y el inicio del XXI" en Mariana Aparicio, Claudia Barona y Juan Carlos Gachúz (coords.), Social Movements in Contemporary International Dynamics. México, UDLAP/UNAM (en prensa).

2019b. "Estado laico y federalismo en México" en Revista Mexicana de Sociología. UNAM, No. 1, enero-marzo, (en prensa).

LEMAITRE RIPOLL, J. 2013. Laicidad y resistencia. Colección de Cuadernos Jorge Carpizo, México, , UNAM/ Instituto de Investigaciones Jurídicas/ Cátedra Extraordinaria Benito Juárez/ Instituto Iberoamericano de Derechos Constitucional.

MANZO, MARIANA. 2016. "Uso estratégico del derecho: reconocimiento del matrimonio de parejas del mismo sexo en Argentina" en Direito \& Práxis [en línea], Vol. 7, No. 15, Río de Janeiro, pp. 175-212. Disponible en http://www.redalyc.org/html/3509/350947688007/ [última consulta: 31 de mayo de 2018].

MARIANIELLO, P. A. 2012. "El activismo judicial, una herramienta de protección constitucional" en Tla-Melaua, Revista de Ciencias Sociales. Año 6, No. 32, abril-septiembre, pp. 46-83. 
NERIA GOVEA, M. DE J. 2015. "Reflexiones sobre la jurisdicción constitucional local desde el modelo constitucional contemporáneo" en Miguel de Jesús Neria Govea y Vhristian Norberto Hernández Aguirre (coords.), Temas selectos de derechos constitucional contemporáneo. Mexicali, Universidad Autónoma de Baja California.

PELÁEZ PADILLA, J. 2017. "Los derechos humanos como repertorio frente al extractivismo minero en México: todo lo que suma ¿importa?" en Estévez, Ariadna y Daniel Vázquez (coords.), 9 Razones para (des) confiar de las luchas por los derechos humanos. México, FLACSO/UNAM.

PICHARDO GALÁN, J. I. 2017. “La 'ideología de género' frentre a los derechos sexuales y reproductivos. el escenario español" en Cadernos Pagu, [en línea] No. 50. Disponible en http://www.scielo.br/pdf/cpa/n50/1809-4449-cpa-18094449201700500009.pdf [última consulta: 20 de marzo de 2018].

POULAT, É. 2012. Nuestra laicidad pública. México, Fondo de Cultura Económica.

RIVERA CASTRO, F. 2013. Laicidad y liberalismo. Colección de Cuadernos Jorge Carpizo, México, UNAM/ Instituto de Investigaciones Jurídicas/ Cátedra Extraordinaria Benito Juárez/ Instituto Iberoamericano de Derechos Constitucional.

RODRÍGUEZ RODRíGUEZ, D. R. 2009. La libertad religiosa en México: XVII años de vigencia de la Ley de Asociaciones Religiosas y Culto Público. Tesis doctoral [en línea]. Disponible en https://repositorio.uam.es/bitstream/handle/10486/4085/28072_rodriguez_rodriguez_rafael.pdf ?sequence=1 [última consulta: 25 de abril de 2018].

SABATIER, P. A. 1988. "An Advocacy Coalition Framework of Policy Change and The Role of PolicyOriented Learning Therein" en Policy Sciences. Vol. 21, No. 2/3, pp. 129-168.

. 1993. "Policy Change over a decade or more", en Paul A. Sabatier \& H. C. Jenkins-Smith (eds.), Policy Change and learningan advocacy coalitions approach. Boulder, Westview Press.

; JENKINS-SMITH, H. C. 1993. "The Advocacy Coalition Framework: Assesment, Revisions and Implications for Scholars and Practitioners" en P. A. Sabatier y H.C. Jenkins-Smtih (eds.), Policy Change and Learning: an advocacy coalition approach. Boulder, Westreview Press, pp. 211-246. 
; JENKINS-SMITH, H. C. 1999. "The Advocacy Coalition Framework. An Assesment, Revisions and Implications for Scholars and Practitioners" en P. A. Sabatier (ed.), Theories of the policy process. Boulder, Westreview Press, pp. 117-168.

SARAT, A.; SCHEINGOLD, S. (eds). 1998. Cause Lawyering. Oxford University Press.

SMULOVITZ, C. 2008. "La política por otros medios: judicialización y movilización legal" en Desarrollo Económico [en línea]. Vol. 48, No. 190/191, Jul-Dic, pp. 287-305. Disponible en https://www.researchgate.net/publication/290190327_La_Politica_por_Otros_Medios_Judicializa cion_y_Movilizacion_Legal_en_Argentina [última consulta: 27 de abril de 2018].

TAYLOR, C. 2014. "How to define secularism?", en Alfred Stepan y Charles Taylor (eds.), Boundaries of Toleration. New York, Columbia University Press, pp. 59-78.

URÍAS HORCASITAS, B. 2015. Rodulfo Brito Foucher: escritos sobre la revolución y la dictadura. México, FCE/UNAM/IIS.

. 2017. "Luis Chico Goerne y la propuesta de un 'modernismo reaccionario' durante el alemanismo (1946-1952)" en Historia y Grafía. Año 24, No. 48, enero-junio, México, Universidad Iberoamericana.

VAGGIONE, J. M. 2005. "Reactive Politicization and Religious Dissidence: The Political Mutations of the Religious" en Social Theory and Practice. Vol. 31, No. 2.

(coord.) 2010. El activismo religioso conservador en Latinoamérica. Colección religión, género y sexualidad. Volumen 3. Córdoba. Hivos/CEA/CONICET.

. 2012. "La 'cultura de la vida'. Desplazamientos estratégicos del activismo católico conservador frente a los derechos sexuales y reproductivos" en Religião e Sociedade[en línea]. Vol.32, No. 2, pp. 57-80. Diponible en http://www.scielo.br/pdf/rs/v32n2/04.pdf [última consulta: 28 de abril de 2018].

2013. Laicidad y sexualidad. Colección de Cuadernos Jorge Carpizo, México, UNAM/ Instituto de Investigaciones Jurídicas/ Cátedra Extraordinaria Benito Juárez/ Instituto Iberoamericano de Derechos Constitucional. 

católica en México".

VECCHIOLI, V. 2009. "Expertise Jurídica y capital militante: reconversiones de recursos escolares, morales y políticos entre los abogados de derechos humanos en la Argentina" en Pro-Posições. Vol. 20, No. 2, mayo-agosto, pp.41-57.

Tramitación del artículo:

Sometido: 13/06/2018

Revisiones requeridas: 20/07/2018

Versión corregida: 03/09/2018

Aceptado: 14/01/2019 